\title{
The Effect of Extracorporeal Membrane Oxygenation on Coronary Perfusion and Regional Blood Flow Distribution ${ }^{1}$
}

\author{
JOHN P. KINSELLA, DALE R. GERSTMANN, AND ADAM A. ROSENBERG
}

\begin{abstract}
Department of Pediatrics, Fitzsimons Army Medical Center, Aurora, Colorado 80013 [J.P.K.]; Department of
Physiology and Medicine, Southwest Foundation for Biomedical Research, San Antonio, Texas 78284 [D.R.G.]; and University of Colorado School of Medicine, Denver, Colorado 80262 [A.A.R.]
\end{abstract}

\begin{abstract}
We studied the distribution of systemic blood flow during venoarterial extracorporeal membrane oxygenation (ECMO) in newborn lambs. We used a three-compartment model that defined partitioning of blood flow to the heart, upper body (brachiocephalic trunk), and lower body (descending aorta). The method used concurrent left ventricular and arterial cannular injections of radiolabeled microspheres to calculate compartment flows and solve the system of equations that defined the partition model. Seven newborn lambs (1-8 d) were studied. A baseline microsphere injection (left ventricle) was performed and the animals were then placed on venoarterial ECMO using right carotid and jugular vein cannulation. The arterial cannula was placed $2-3.5 \mathrm{~cm}$ above the aortic valve. After stabilization on ECMO flow rates of 50 and $100 \mathrm{~mL} / \mathrm{min} /$ $\mathrm{kg}$, differently labeled microspheres were injected simultaneously into the left ventricle and arterial limb of the ECMO circuit. From the flow partition model, distribution of blood flow was calculated. We found that ECMO did not change the overall distribution of blood flow to the three compartments studied. However, blood flow from the ECMO circuit was preferentially directed to the upper body. Coronary arterial and abdominal organ blood flow was predominantly derived from the left ventricle at both ECMO flow rates. Coronary arterial blood flow did not significantly change on ECMO $(253 \pm 45 \mathrm{~mL} / \mathrm{min} / 100 \mathrm{~g}$ at $50 \mathrm{~mL} / \mathrm{min} / \mathrm{kg} \mathrm{ECMO} \mathrm{flow;} 246 \pm 50 \mathrm{~mL} / \mathrm{min} / 100 \mathrm{~g}$ at $100 \mathrm{~mL} / \mathrm{min} / \mathrm{kg} \mathrm{ECMO} \mathrm{flow)} \mathrm{compared} \mathrm{to} \mathrm{baseline} \mathrm{(186}$ $\pm 31 \mathrm{~mL} / \mathrm{min} / 100 \mathrm{~g}$ ). We conclude that coronary arterial blood flow is not compromised at the ECMO flow rates studied; however, the predominate source of coronary flow is from the left ventricle despite proximate placement of the arterial cannula. (Pediatr Res 31: 80-84, 1992)
\end{abstract}

\section{Abbreviations}

ECMO, extracorporeal membrane oxygenation LVO, left ventricular output

Received March 26, 1991; accepted July 24, 1991.

Correspondence: John P. Kinsella, M.D., Division of Neonatology, Box B070, The Children's Hospital, 1056 East 19th Ave., Denver, CO 80218.

Supported by National Institutes of Health Grant RO1 HL36301-04 and the U.S. Army Medical Research and Development Command.

Presented in part at the 60th Annual Meeting of the Society for Pediatric Research, New Orleans, LA, April 29-May 2, 1991. Opinions, interpretations, conclusions, and recommendations are those of the authors and are not necessarily endorsed by the U.S. Army.
Venoarterial ECMO is used to provide partial heart-lung bypass support for the neonate with severe cardiopulmonary failure unresponsive to other therapies. During ECMO, systemic perfusion derives from both the ECMO arterial cannula and LVO. Regional blood flow distribution during ECMO is not well characterized because of difficulties in studying the distribution of these two separate sources of systemic perfusion.

We hypothesized that mixing of blood from the ECMO arterial cannula and left ventricle would be incomplete, resulting in preferential streaming of each flow source. To investigate the distribution of systemic blood flow during ECMO, we used a three-compartment model that defined partitioning of blood flow to the heart, upper body (brachiocephalic trunk), and lower body (descending aorta). We studied the distribution of blood flow during ECMO in newborn lambs using a modification of the radiolabeled microsphere technique and this partitioning model.

\section{MATERIALS AND METHODS}

Animals. Seven mixed-breed newborn lambs (aged 1-8 d, weight $3.9-6.2 \mathrm{~kg}$ ) were studied.

Surgical procedures. Lambs were immobilized with ketamine hydrochloride i.v. Local infiltration of $1 \%$ lidocaine hydrochloride was used during instrumentation. Polyvinyl chloride catheters $(0.034$ inches inner diameter, 0.054 inches outer diameter; Martech Medical Products, Lansdale, PA) were placed in a femoral vein for fluid administration and in a femoral artery for blood pressure monitoring and reference sample withdrawal during microsphere injections. The left carotid artery was cannulated, without sacrificing the vessel, for reference sample withdrawal reflecting brachiocephalic trunk distribution. A catheter was advanced from a femoral artery to the left ventricle for microsphere injections. Proper placement of the left ventricular catheter was verified by observing the characteristic ventricular wave form obtained as the catheter tip was advanced $2.5 \mathrm{~cm}$ past the aortic valve. This procedure reliably positions the catheter in the apex of the left ventricle. After completion of catheter placement, the animals were given pancuronium $(0.1 \mathrm{mg} / \mathrm{kg}$ i.v. $)$, were endotracheally intubated, and were mechanically ventilated using an infant ventilator (Bird Co., Palm Springs, CA). Ventilator settings were adjusted to obtain arterial blood gas measurements within normal ranges.

This research was conducted in compliance with the Animal Welfare Act and other federal statutes and regulations relating to experiments involving animals. The authors adhered to the principles stated in the Guide for the Care and Use of Laboratory Animals, NIH publication 85-23, 1985.

Physiologic measurements. Distribution of blood flow was measured using the radiolabeled microsphere technique (1-3). Microspheres $15 \mu \mathrm{m}$ in diameter labeled with ${ }^{85} \mathrm{Sr},{ }^{153} \mathrm{Gd},{ }^{95} \mathrm{Nb}$, ${ }^{46} \mathrm{Sc}$, and ${ }^{113} \mathrm{Sn}(3 \mathrm{M}$, St. Paul, MN) were used. During microsphere injections, arterial reference blood samples were with- 
drawn into glass syringes at $2.40 \mathrm{~mL} / \mathrm{min}$ by a precalibrated syringe pump (Harvard Apparatus, Dover, MA). Withdrawal began $1 \mathrm{~min}$ before microsphere injections and continued for 1 min after completion. The microsphere injections were not associated with changes in heart rate or blood pressure.

After completion of the experiments, the animals were killed using T-61 euthanasia solution (American Hoechst, Somerville, $\mathrm{NJ}$ ), the position of the catheters was verified, and organs were excised for analysis of radioactivity content. The carcass was divided into upper and lower portions at the 7 th thoracic vertebra and homogenized to uniform consistency, and representative samples were taken for gamma counting. Radioactivity in all samples was determined using a three-channel gamma counter (Tracor Analytic, Des Plaines, IL).

Blood samples for $\mathrm{pH}, \mathrm{PO}_{2}$, and $\mathrm{PCO}_{2}$ were withdrawn anaerobically into Natelson glass pipettes and analyzed at $39.5^{\circ} \mathrm{C}$ using a Radiometer OSM3 blood gas analyzer (Copenhagen, Denmark). Blood $\mathrm{Hb}$ concentration and oxyhemoglobin saturation were measured colorimetrically in duplicate using a hemoximeter (Radiometer), and oxygen content was calculated as the product of $\mathrm{Hb}$ concentration and oxyhemoglobin saturation.

Experimental procedures. A control microsphere injection was performed and the animals were then placed on venoarterial ECMO using right carotid and jugular vein cannulation. The ECMO circuit and methods used were similar to those used for ECMO in the clinical setting. A 12 or $14 \mathrm{Fr}$ venous ECMO cannula and a 9.6 Fr arterial cannula (Gesco International Inc., San Antonio, TX) were placed through a paramedian neck incision. The arterial cannula was placed $2-3.5 \mathrm{~cm}$ above the aortic valve using previously determined external landmarks. The ECMO circuit consisted of a standard roller pump (Precision Blood Pump, Cobe Laboratories Inc., Lakewood, CO), a 0.8-M ${ }^{2}$ silicone membrane oxygenator (Sci-Med, Life Systems Inc., Minneapolis, MN), a heat exchanger (Sci-Med), and a $50-\mathrm{mL}$ reservoir placed within a servoregulating device limiting roller pump output to available venous blood.

After stabilization on ECMO flow rates of 50 and $100 \mathrm{~mL} /$ $\mathrm{min} / \mathrm{kg}$, simultaneous injections of differently labeled microspheres into the left ventricle and arterial limb of the ECMO circuit were performed. Paired arterial reference samples were withdrawn from the left carotid artery and descending aorta.

Partitioning model. The presence of two separate sources of systemic blood flow during ECMO (arterial cannula and left ventricle) creates unique problems in the application of the microsphere method. The usual application of the microsphere technique uses the injection of a single isotope with a single arterial reference sample withdrawal site (serving as the surrogate organ). However, this approach is only valid if complete mixing of the two sources of blood flow is achieved at the aortic valve. We hypothesized that complete mixing at the aortic valve would not occur; therefore, a three-compartment mathematical model devised by one of the authors (D.R.G.) was used to describe partitioning of systemic blood flow to the heart, upper body (brachiocephalic trunk), and lower body (descending aorta). The relative numbers of microspheres trapped within each reference sample and organ of interest were used to calculate compartment flows and solve the system of equations that defined the partition model. From this model the contribution of flow from ECMO and from LVO could be determined to all three compartments (heart, upper body, lower body) (see Appendix).

Statistical analysis. Differences between baseline measurements and those made at 50 and $100 \mathrm{~mL} / \mathrm{min} / \mathrm{kg}$ of ECMO flow were analyzed using analysis of variance with Fisher's least significant difference test for post hoc comparisons. Differences in blood flow derivation from LVO and ECMO at each experimental condition were analyzed using unpaired $t$ tests with Bonferroni adjustment. The level of statistical significance was set at 0.05 . Data are reported as mean \pm SEM.

\section{RESULTS}

Physiologic measurements at baseline and each ECMO flow rate are shown in Table 1 . There were no significant differences noted for $\mathrm{PaCO}_{2}, \mathrm{O}_{2}$ content, mean arterial pressure, or heart rate at each experimental condition. Control values for arterial $\mathrm{pH}$ and $\mathrm{PaO}_{2}$ were significantly different than measurements made during ECMO at each flow rate.

We found that ECMO did not change the overall distribution of blood flow to the three compartments studied compared to control (Fig. 1). Approximately $30 \%$ of total systemic flow was directed to the upper body and approximately $60 \%$ to the lower body at control and each ECMO flow rate.

However, blood flow from the ECMO circuit was preferentially directed to the upper body (Fig. $2 A)(p<0.001)$. Descending aortic blood flow was predominantly derived from the left ventricle at both ECMO flow rates (Fig. $2 B)(p<0.001)$, as was coronary arterial blood flow (Fig. $2 C)(p<0.001)$.

Despite changes in the derivation of blood flow to organs after initiation of ECMO, there was no significant change in coronary arterial blood flow (mL/min/100 g) (Fig. 3) $(p=0.49)$.

\section{DISCUSSION}

The distribution of systemic blood flow during extracorporeal circulation has been of keen interest to investigators since the advent of this technique for use during cardiac surgery (4). Early studies focused on the distribution of blood flow during total cardiopulmonary bypass, since the technique was predominantly used for short periods intraoperatively $(5,6)$. However, prolonged partial cardiopulmonary bypass (ECMO) has gained more widespread acceptance in recent years as an alternative therapy for neonates with life-threatening, reversible cardiopulmonary failure.

There are important features that distinguish ECMO from total cardiopulmonary bypass. During ECMO the venous return to the right atrium is only partially captured by the venous drainage cannula. Therefore, total systemic blood flow is the sum of residual left ventricular output and the ECMO pump flow rate. Moreover, techniques used for organ preservation during total cardiopulmonary bypass (cardioplegia solutions,

Table 1. Physiological variables at each microsphere injection time point*

\begin{tabular}{lcccr}
\hline & & ECMO & $\begin{array}{c}\text { ECMO } \\
(100 \mathrm{~mL} / \mathrm{min} / \mathrm{kg})\end{array}$ & $\begin{array}{c}\text { ANOVA } \\
(p \text { value })\end{array}$ \\
\hline $\mathrm{pH}$ & Control & $(50 \mathrm{~mL} / \mathrm{min} / \mathrm{kg})$ & $7.28 \pm 0.05$ & $<0.01$ \\
$\mathrm{PaCO}_{2}(\mathrm{kPa})$ & $7.35 \pm 0.02 \dagger$ & $7.29 \pm 0.14$ & $4.7 \pm 0.03$ & 0.49 \\
$\mathrm{PaO}_{2}(\mathrm{kPa})$ & $5.1 \pm 0.3$ & $4.7 \pm 0.3$ & $56.7 \pm 4.8$ & $<.01$ \\
$\mathrm{O}_{2} \operatorname{content}(\mu \mathrm{M})$ & $6.7 \pm 0.3 \pm$ & $47.6 \pm 7.9$ & $6.0 \pm 0.2$ & 0.14 \\
Heart rate & $241 \pm 20$ & $212 \pm 14$ & $201 \pm 13$ & 0.19 \\
MABP $(\mathrm{kPa})$ & $11.5 \pm 0.7$ & $9.5 \pm 0.4$ & $10.7 \pm 1.3$ & 0.31 \\
\hline
\end{tabular}

* ANOVA, analysis of variance; $\mathrm{PaCO}_{2}$, arterial $\mathrm{CO}_{2}$ partial pressure; $\mathrm{PaO}_{2}$, arterial $\mathrm{O}_{2}$ partial pressure; MABP, mean arterial blood pressure. $\mathrm{mm} \mathrm{Hg}=\mathrm{kPa}(7.50)$.

$\dagger p<0.05$ vs $50 / 100 \mathrm{~mL} / \mathrm{min} / \mathrm{kg}$.

$\ddagger p<0.001$ vs $50 / 100 \mathrm{~mL} / \mathrm{min} / \mathrm{kg}$. 


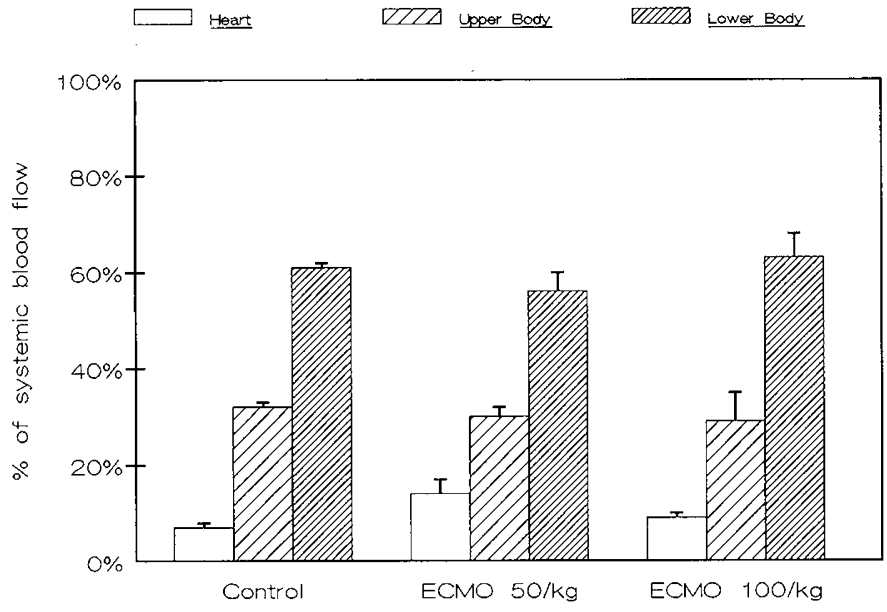

Fig. 1. Partitioning of total systemic blood flow to heart, upper body, and lower body for control baseline, ECMO $50 \mathrm{~mL} / \mathrm{min} / \mathrm{kg}$, and ECMO $100 \mathrm{~mL} / \mathrm{min} / \mathrm{kg}$ flow rates.

hypothermia) are not applicable during ECMO. Therefore, maintenance of adequate coronary arterial blood flow during ECMO is of paramount importance.

Measurements of the distribution of systemic blood flow during ECMO are complicated by the presence of two sources of systemic arterial blood, that is, the left ventricle and the ECMO arterial cannula. To define the distribution of systemic blood flow in the presence of these two input sources, we injected microspheres simultaneously into each source and determined partitioning of flow using a mathematical model. The results demonstrated that, despite placement of the arterial cannula tip close to the aortic valve, there was incomplete mixing of the two sources of blood flow at the aortic root despite pump flow rates approximating $50 \%$ of the baseline (pre-ECMO) cardiac output. Thus, streaming of the two sources of blood flow occurred, resulting in preferential partitioning of the ECMO arterial cannula flow to the upper body, and LVO to the lower body and heart.

Other investigators have studied the distribution of blood flow during ECMO $(7,8)$, with conflicting results. Nowlen et al. (7) used single injections of technetium-labeled microaggregated albumin to measure the relative distribution of LVO versus ECMO arterial cannula flow compared to controls in a rabbit model. These authors reported decreased blood flow from the arterial cannula to the brain and heart in this model at $30 \mathrm{~mL} /$ $\mathrm{min} / \mathrm{kg}$ of ECMO flow. Smith et al. (8) used the same method in a lamb model at $50 \mathrm{~mL} / \mathrm{min} / \mathrm{kg}$ of ECMO flow to measure the distribution of arterial cannula flow compared to the distribution of LVO in a control group. Their results showed a significantly smaller percentage of ECMO arterial cannula flow to the heart, but a significantly larger percentage delivered to the brain compared to the control group. However, in both of these studies, interpretation of the results is limited by the fact that total distribution of systemic blood flow could not be assessed with the use of a single injection of particulate indicator. In contrast, the method that we used allowed simultaneous determination of the distribution of LVO and ECMO flow in each animal through the use of concurrent injections of microspheres and paired arterial reference sample withdrawals.

The question of proper siting of the arterial cannula to achieve adequate coronary arterial oxygenation has critical relevance to the recent application of ECMO in postoperative cardiac surgery support (9). Although ECMO did not compromise coronary arterial perfusion in our model, it is apparent that oxygen delivery to the heart is more closely related to intrinsic pulmonary status (pulmonary venous saturation, LVO) than to ECMO pump arterial oxygen content. These findings are supported by the studies of Hill et al. (10) and Soeter et al. (11), who found that
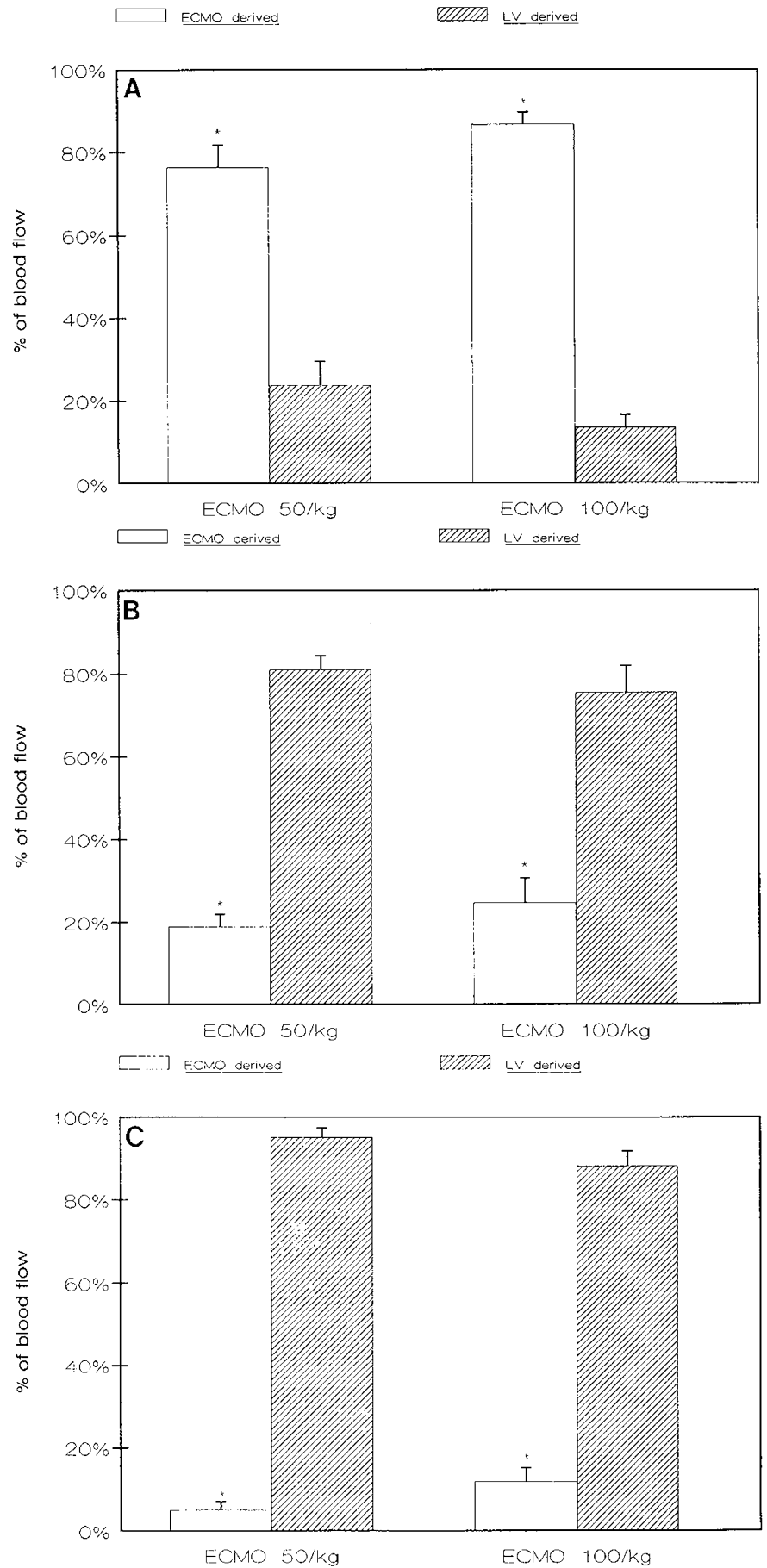

Fig. 2. Percentage of total flow to each compartment derived from ECMO arterial cannula vs left ventricle. ${ }^{*}, p<0.001$. $A$, Upper body; $B$, lower body; and $C$, heart.

even small amounts of LVO during partial bypass precluded retrograde perfusion of the aortic arch using femoral arterial cannulation. Moreover, Secker-Walker et al. (12), using ECMO arterial return to the ascending aorta in adult sheep, found that an $85 \%$ bypass flow was required for a $25 \%$ increment in oxygenated blood to the coronary arteries. Similarly, Gerstmann et al. (13) reported that coronary arterial flow predominately derived from LVO in a baboon model of ECMO.

The delivery of well-oxygenated arterial cannula blood may also be compromised during venoarterial ECMO as it is currently used in the human newborn with severe cardiopulmonary failure. As noted by Dudell et al. (14) and Martin et al. (15), the syndrome of cardiac stun manifests in markedly compromised 


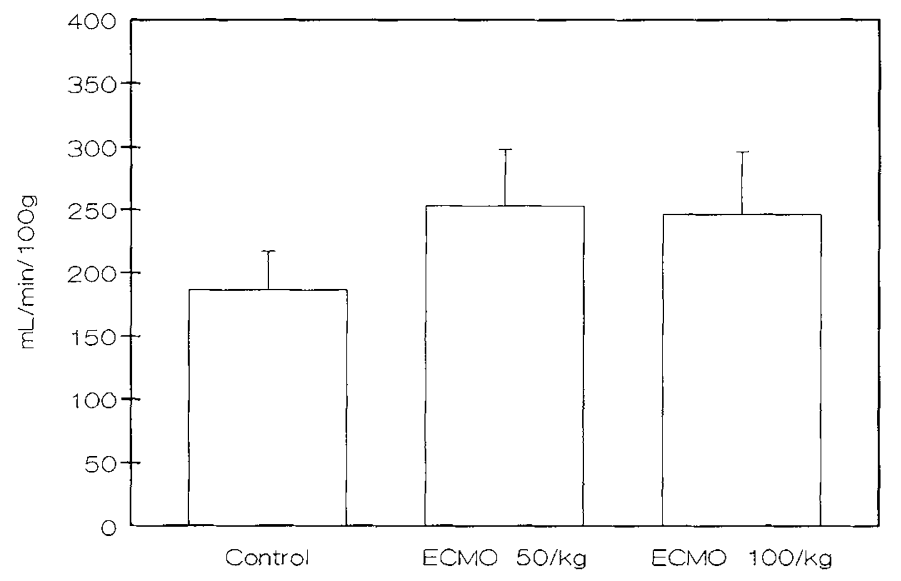

Fig. 3. Coronary arterial blood flow $(\mathrm{mL} / \mathrm{min} / 100 \mathrm{~g})$ for control, ECMO $50 \mathrm{~mL} / \mathrm{min} / \mathrm{kg}$, and ECMO $100 \mathrm{~mL} / \mathrm{min} / \mathrm{kg}$ flow rates.

cardiac performance in a subset of infants after initiation of ECMO. These authors have suggested that perfusion of the coronary arteries with desaturated blood derived from the left ventricle may contribute to the cardiac stun syndrome seen in some neonatal ECMO patients. The findings of our studies lend support to this hypothesis.

It is possible that, in the clinical setting, echocardiographic demonstration of turbulence created by the arterial cannula at the aortic valve would be evidence for adequate retrograde flow of well-oxygenated pump blood to the coronary arteries. However, it should be recognized that if sufficient retrograde flow from the arterial cannula is achieved by placement of the cannula tip very close to the aortic valve or by very high bypass flows, then competence of the aortic valve may be compromised, resulting in aortic insufficiency or frank injury. Thus, recommendations for optimal placement of the arterial cannula during ECMO await further study.

Conclusion. In this model, although ECMO did not change the overall distribution of blood flow, mixing of the two sources of blood flow (ECMO and LVO) was not complete. This resulted in preferential streaming of ECMO flow to the upper body and LVO to the lower body. Coronary arterial blood flow was not compromised at the ECMO flow rates studied; however, the source of coronary arterial blood flow was predominantly left ventricular despite proximate placement of the arterial cannula. As such, the delivery of well-oxygenated blood to the heart may be suboptimal under certain conditions during ECMO. These findings suggest a mechanical explanation for cardiac stun in certain patients treated with ECMO and have important clinical implications when ECMO is instituted for the postoperative management of compromised cardiac performance.

\section{REFERENCES}

1. Heymann MA, Payne BD, Hoffman JIE, Rudolph AM 1977 Blood flow measurements with radionuclide-labeled particles. Prog Cardiovasc Dis 20:55-79

2. Rosenberg AA, Jones MD, Koehler RC, Traystman RG, Lister G 1983 Precautions for measuring blood flow during anemia with the microsphere technique. Am J Physiol 244:H308-H311

3. Rosenberg AA 1986 Cerebral blood flow and $\mathrm{O}_{2}$ metabolism after asphyxia in neonatal lambs. Pediatr Res 20:778-782

4. Gibbon JH 1954 Application of a mechanical heart and lung apparatus to cardiac surgery. Minn Med 37:171-180

5. Rudy Jr LW, Heymann MA, Edmunds Jr L.H 1973 Distribution of systemic blood flow during cardiopulmonary bypass. J Appl Physiol 34:194-200

6. Rudy LW, Boucher JK, Edmunds Jr LH 1972 The effect of deep hypothermia and circulatory arrest on the distribution of systemic blood flow in rhesus monkeys. J Thorac Cardiovasc Surg 64:706-712

7. Nowlen TT, Salley SO, Whittlesey GC, Kundu SK, Maniaci NA, Henry RL Klein MD 1989 Regional blood flow distribution during extracorporea membrane oxygenation in rabbits. J Thorac Cardiovasc Surg 98:1138-1143

8. Smith HG, Whittlesey GC, Kundu SK, Salley SO, Kuhns LR, Chang CH, Klein MD 1989 Regional blood flow during extracorporeal membrane oxygenation in lambs. Trans Am Soc Artif Intern Organs 35:657-660
9. Kanter KR, Pennington DG, Weber TR, Zambie MA, Braun P, Martychenko V 1987 Extracorporeal membrane oxygenation for postoperative cardiac support in children. J Thorac Cardiovasc Surg 93:27-35

10. Hill JD, de Leval MR, Fallat RJ, Bramson ML, Eberhart RC, Schulte HD Osborn JJ, Barber R, Gerbode F 1972 Acute respiratory insufficiency: treatment with prolonged extracorporeal oxygenation. J Thorac Cardiovasc Surg 64:551-562

11. Soeter JR, Smith GT, Anema RJ, Suehiro GT, McNamara JJ 1973 Distribution of oxygenated blood in femoral and brachial artery perfusion during venoarterial bypass in primates. $\mathrm{J}$ Thorac Cardiovasc Surg 65:825-829

12. Secker-Walker JS, Edmonds JF, Spratt EH, Conn AW 1976 The source of coronary perfusion during partial bypass for extracorporeal membrane oxygenation (ECMO). Ann Thorac Surg 21:138-143

13. Gerstmann DR, Nose K, Kinsella JP, Cornish JD 1989 Left carotid artery and coronary arterial flow partitioning during neonatal ECMO. Pediatr Res 25:37A(abstr)

14. Dudell G, Evans M, Cornish JD 1991 Partition of blood flow during venoarterial extracorporeal membrane oxygenation (ECMO). Pediatr Res 29:212A(abstr)

15. Martin GR, Short BL, Abbott C, O'Brien AM 1991 Cardiac stun in infants undergoing extracorporeal membrane oxygenation. J Thorac Cardiovasc Surg 101:607-611

\section{APPENDIX}

There are two independent sources of systemic blood flow $\left(Q_{e s}\right)$ during ECMO. These sources are the subject's own left ventricular output $\left(\mathrm{Q}_{\mathrm{lvo}}\right)$ and the additional contribution from the ECMO arterial cannula $\left(\mathrm{Q}_{\mathrm{ecmo}}\right)$. In the three-partition model, we assume that $\mathrm{Q}_{\mathrm{es}}$ supplies three compartments via three separate routes. These are: $I$ ) the heart via coronary arteries (cor); 2 ) the patent branches of the brachiocephalic trunk, which we will label together as the upper body (ub); and 3) the branches of the aorta distal to the brachiocephalic trunk which is, predominantly, descending aortic blood flow to the lower body (lb). These three routes represent the three flow $(\mathrm{Q})$ compartments of the model.

$$
\mathrm{Q}_{\mathrm{es}}=\mathrm{Q}_{\mathrm{cor}}+\mathrm{Q}_{\mathrm{ub}}+\mathrm{Q}_{\mathrm{lb}}
$$

Each component of systemic blood flow $\left(\mathrm{Q}_{\mathrm{cor}}, \mathrm{Q}_{\mathrm{ub}}, \mathrm{Q}_{\mathrm{lb}}\right)$ must be composed of some fraction of each inflow source $\left(\mathrm{Q}_{\mathrm{Ivo}}, \mathrm{Q}_{\mathrm{ecmo}}\right)$. These fractions are the partition coefficients.

$$
\begin{aligned}
& Q_{\text {cor }}=a_{1} \cdot Q_{1 v o}+b_{1} \cdot Q_{\text {ecmo }} \\
& Q_{\text {ub }}=a_{2} \cdot Q_{1 v o}+b_{2} \cdot Q_{\text {ecmo }} \\
& Q_{\text {lb }}=a_{3} \cdot Q_{1 v o}+b_{3} \cdot Q_{\text {ecmo }}
\end{aligned}
$$

In these equations, $a$ and $b$ are the partition coefficients, representing that fraction of each inflow source contributing to the total flow of each partition compartment. Of necessity, $a_{1}+a_{2}$ $+a_{3}=1=b_{1}+b_{2}+b_{3}$, inasmuch as flow sources must be conserved. For measurement purposes, flow is sampled at known rates from two of the compartments; that is, there are two arterial reference samples drawn during each measurement on ECMO. One is a branch of the left carotid artery (ub-ref) (representing brachiocephalic trunk distribution; upper body), and the other is an abdominal aortic reference sample (lb-ref) (representing descending aortic flow; lower body). These reference flows must be some fraction of the total flow to their respective compartments. These fraction constants are labeled as $\mathrm{C}_{\mathrm{ub}}$ and $\mathrm{C}_{\mathrm{lb}}$. The flows $\mathrm{Q}_{\mathrm{ub}-\mathrm{ref}}$ and $\mathrm{Q}_{\mathrm{lb} \text {-ref }}$ are the withdrawal rates of the two syringe pumps in $\mathrm{mL} / \mathrm{min}$. These values are known and are shown in bold type in the equations below

$$
\begin{aligned}
& Q_{\mathrm{ub}-\mathrm{ref}}=C_{\mathrm{ub}} \cdot Q_{\mathrm{ub}}=C_{\mathrm{ub}} \cdot\left(\mathrm{a}_{2} \cdot \mathrm{Q}_{\mathrm{lvo}}+\mathrm{b}_{2} \cdot \mathrm{Q}_{\mathrm{ecmo}}\right) \\
& \mathrm{Q}_{\mathrm{lb} \text {-ref }}=\mathrm{C}_{\mathrm{lb}} \cdot \mathrm{Q}_{\mathrm{lb}}=\mathrm{C}_{\mathrm{lb}} \cdot\left(\mathrm{a}_{3} \cdot \mathrm{Q}_{\mathrm{lvo}}+\mathrm{b}_{3} \cdot \mathrm{Q}_{\mathrm{ecmo}}\right)
\end{aligned}
$$

During ECMO, two aliquots of microspheres labeled with different isotopes are simultaneously injected, one into the left ventricle and the other into the arterial limb of the ECMO circuit. The total number of microspheres of isotope 1 (left ventricle) will be labeled ${ }^{1} \mathrm{~N}$, and for isotope 2 (ECMO circuit), ${ }^{2} \mathrm{~N}$. These values are known after necropsy by summing the counts for each isotope from all tissues.

Also known after the experiment are the number of micro- 
Also known after the experiment are the number of microspheres delivered to the heart for each isotope $\left({ }^{1} \mathrm{~N}_{\mathrm{hr}},{ }^{2} \mathrm{~N}_{\mathrm{hr}}\right)$, and the number that appear in each of the arterial reference samples: ( $\left.{ }^{1} \mathrm{~N}_{\text {ub-ref, }},{ }^{2} \mathrm{~N}_{\mathrm{ub}-\mathrm{ref}}\right)$ and $\left({ }^{1} \mathrm{~N}_{\mathrm{lb}-\mathrm{ref}},{ }^{2} \mathrm{~N}_{\mathrm{lb}-\mathrm{ref}}\right)$. From these numbers the count ratios, $\mathrm{R}$, are calculated.

$$
\begin{array}{rlrl}
{ }^{1} \mathrm{R}_{\text {hrt }} & ={ }^{1} \mathrm{~N}_{\text {hrt }} /{ }^{1} \mathrm{~N} ; & { }^{2} \mathrm{R}_{\text {hrt }} & ={ }^{2} \mathrm{~N}_{\text {hrt }} /{ }^{2} \mathrm{~N} \\
{ }^{1} \mathrm{R}_{\mathrm{ub} \text {-ref }} & ={ }^{1} \mathrm{~N}_{\text {ub-ref }} /{ }^{1} \mathrm{~N} ; & { }^{2} \mathrm{R}_{\text {ub-ref }}={ }^{2} \mathrm{~N}_{\text {ub-ref }} /{ }^{2} \mathrm{~N} \\
{ }^{1} \mathrm{R}_{\mathrm{lb} \text {-ref }}={ }^{1} \mathrm{~N}_{\text {lb-ref }} /{ }^{1} \mathrm{~N} ; & { }^{2} \mathrm{R}_{\mathrm{lb} \text {-ref }}={ }^{2} \mathrm{~N}_{\text {lb-ref }} /{ }^{2} \mathrm{~N}
\end{array}
$$

Because microsphere distribution parallels flow distribution, the fraction of microspheres in each end organ or arterial reference sample must be equal to the fraction of flow reaching that site. Thus, $a_{1}, b_{1}$, and $R$ are related.

$$
\begin{array}{rlrl}
{ }^{1} \mathrm{R}_{\mathrm{hrt}} & =\mathrm{a}_{1} ; & { }^{2} \mathrm{R}_{\mathrm{hrt}} & =\mathrm{b}_{1} \\
{ }^{1} \mathrm{R}_{\mathrm{ub} \text {-ref }} & =\mathrm{a}_{2} \cdot \mathrm{C}_{\mathrm{ub}} ; & { }^{2} \mathrm{R}_{\mathrm{ub}-\mathrm{ref}} & =\mathrm{b}_{2} \cdot \mathrm{C}_{\mathrm{ub}} \\
{ }^{1} \mathrm{R}_{\mathrm{lb} \text {-ref }} & =\mathrm{a}_{3} \cdot \mathrm{C}_{\mathrm{lb}} ; & { }^{2} \mathrm{R}_{\mathrm{lb} \text {-ref }}=\mathrm{b}_{3} \cdot \mathrm{C}_{\mathrm{lb}}
\end{array}
$$

The remainder of the model involves solving mathematically for the fraction constants and the flows. To help simplify this process, the ratio constants, $\mathrm{K}$, are calculated.

$$
\begin{aligned}
\mathrm{K}_{\mathrm{ub}-\mathrm{ref}} & =\left(\mathrm{a}_{2} / \mathrm{b}_{2}\right)=\left({ }^{1} \mathrm{R}_{\mathrm{ub}-\mathrm{ref}} /{ }^{2} \mathrm{R}_{\mathrm{ub}-\mathrm{ref}}\right) \\
\mathrm{K}_{\mathrm{lb}-\mathrm{ref}} & =\left(\mathrm{a}_{3} / \mathrm{b}_{3}\right)=\left({ }^{1} \mathrm{R}_{\mathrm{lb} \text {-ref }} /{ }^{2} \mathrm{R}_{\mathrm{lb}-\mathrm{ref}}\right)
\end{aligned}
$$

Derivation:

$$
\begin{aligned}
\mathrm{a}_{1}+\mathrm{a}_{2}+\mathrm{a}_{3} & =1 \\
\mathrm{a}_{2}+\mathrm{a}_{3} & =\left(1-\mathrm{a}_{1}\right) \\
\left(\mathrm{b}_{2} \cdot \mathrm{K}_{\mathrm{ub}-\text {-ref }}\right)+\left(\mathrm{b}_{3} \cdot \mathrm{K}_{\mathrm{ib} \text {-ref }}\right) & =\left(1-{ }^{\prime} \mathrm{R}_{\mathrm{hr}}\right)
\end{aligned}
$$

$$
\begin{aligned}
& \left(1-b_{1}-b_{3}\right) \cdot K_{u b-r e f}+\left(b_{3} \cdot K_{1 b-r e f}\right)=\left(1-{ }^{\prime} R_{h r r}\right) \\
& \left(1-b_{1}\right) \cdot K_{u b-r e f}+b_{3} \cdot\left(K_{1 b-r e f}-K_{u b-r e f}\right)=\left(1-{ }^{\prime} R_{h r r}\right) \\
& b_{3} \cdot\left(K_{\text {lb-ref }}-K_{u b-r e f}\right)=\left(1-{ }^{\prime} R_{h r}\right)-\left(1-b_{1}\right) \cdot K_{u b-r e f} \\
& b_{3}=\left[\left(1-{ }^{\prime} R_{h r t}\right)-\left(1-{ }^{2} R_{h r}\right)\right. \\
& \cdot \mathrm{K}_{\mathrm{ub}-\mathrm{rct}} \mathrm{f} /\left(\mathrm{K}_{\mathrm{lb}-\mathrm{rcf}}-\mathrm{K}_{\mathrm{ub}-\mathrm{ref}}\right) \\
& \mathrm{b}_{2}=\left(1-{ }^{2} \mathrm{R}_{\mathrm{hrt}}-\mathrm{b}_{3}\right) \\
& \mathrm{b}_{1}={ }^{2} \mathrm{R}_{\mathrm{hr}} \\
& \mathrm{a}_{3}=\mathrm{b}_{3} \cdot \mathrm{K}_{\mathrm{lb}-\mathrm{ref}} \\
& \mathrm{a}_{2}=\mathrm{b}_{2} \cdot \mathrm{K}_{\mathrm{ub}-\mathrm{ref}} \\
& a_{1}={ }^{1} R_{h r t} \\
& \mathrm{C}_{\mathrm{ub}}={ }^{1} \mathrm{R}_{\mathrm{ub}-\mathrm{rcf}} / \mathrm{a}_{2} \\
& \mathrm{C}_{\mathrm{lb}}={ }^{1} \mathrm{R}_{\mathrm{lb}-\mathrm{rce}} / \mathrm{a}_{3} \\
& \mathrm{Qub}_{\mathrm{ub}}=\mathrm{Q}_{\mathrm{ub}-\mathrm{rc} /} / \mathrm{C}_{\mathrm{ub}} \\
& \mathrm{Q}_{\mathrm{lb}}=\mathrm{Q}_{\mathrm{Ib}-\mathrm{res}} / \mathrm{C}_{\mathrm{lb}} \\
& \mathrm{Q}_{\mathrm{ecmo}} \cdot\left(\mathrm{a}_{3} \cdot \mathrm{b}_{2}-\mathrm{a}_{2} \cdot \mathrm{b}_{3}\right)=\left(\mathrm{a}_{3} \cdot \mathrm{Qub}_{\mathrm{ub}}-\mathrm{a}_{2} \cdot \mathrm{Q}_{\mathrm{lb}}\right) \\
& \mathrm{Q}_{\mathrm{ccmo}}=\left(\mathrm{a}_{3} \cdot \mathrm{Q}_{\mathrm{ub}}-\mathrm{a}_{2} \cdot \mathrm{Q}_{\mathrm{lb}}\right) /\left(\mathrm{a}_{3} \cdot \mathrm{b}_{2}-\mathrm{a}_{2} \cdot \mathrm{b}_{3}\right) \\
& \mathrm{Q}_{\mathrm{lvo}}=\left(\mathrm{Q}_{\mathrm{lb}}-\mathrm{b}_{3} \cdot \mathrm{Q}_{\mathrm{ecmo}}\right) / \mathrm{a}_{3} \\
& \mathrm{Q}_{\mathrm{es}}=\mathrm{Q}_{\mathrm{ivo}}+\mathrm{Q}_{\mathrm{ccmo}} \\
& \mathrm{Q}_{\mathrm{cor}}=\mathrm{Q}_{\mathrm{es}}-\mathrm{Q}_{\mathrm{ub}}-\mathrm{Q}_{\mathrm{lb}}
\end{aligned}
$$

